Beate Taudte-Repp

\section{Der Palmengarten - Ein Führer durch Frankfurts grüne Oase. Dritte, vollständig überarbeitete und erweiterte Auflage in neuer Aufmachung.}

Societäts-Verlag, Frankfurt am Main 2012, 168 Seiten, Smart-Cover mit über 100 Farbfotografien, Euro 12,80; ISBN 978-3-942921-73-2

Rechtzeitig zur Neueröffnung des Gesellschaftshauses im Herbst 2012 hat die Journalistin BeAte TAudteRepp eine Neuauflage ihres erstmals 2005 erschienenen Führers durch den Frankfurter Palmengarten fertiggestellt. Der mit 32 zusätzlichen, nun auf 168 Seiten erweiterte Band gibt detailliert Auskunft über den Traditionsgarten sowie die vielfältigen Pflanzen und Sammlungen, die den internationalen Ruf von Frankfurts grüner Oase seit jeher begründen. Ein neu hinzugekommenes Stichwort-Register erlaubt ein schnelles

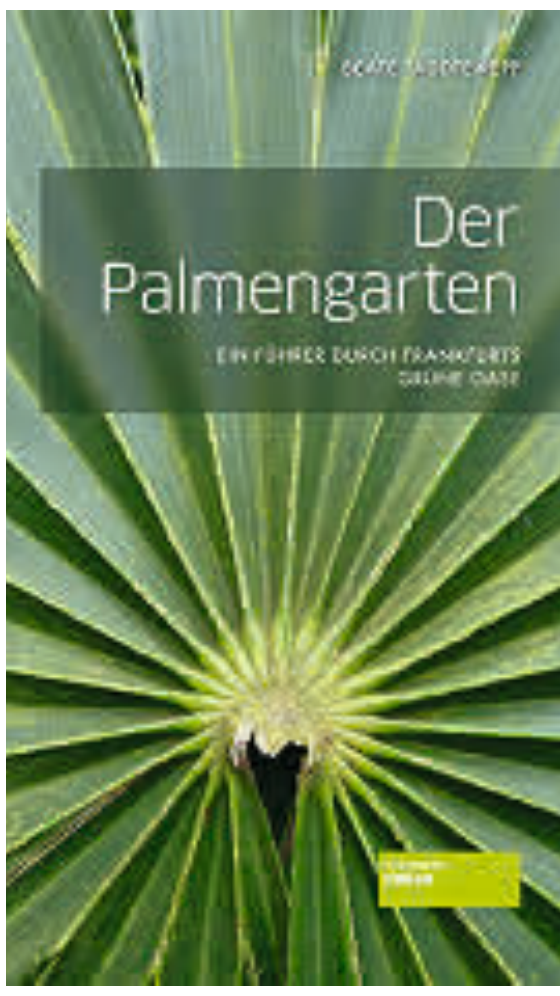
Nachschlagen zu allen Schauhäusern, Themengärten etc., die den Besucher an den verschiedensten Stationen seines Rundgangs interessieren mögen.

Der Rundgang durch den 22 ha großen Garten im Hauptkapitel „Der Garten und seine Schauhäuser" wurde den jüngsten Neuerungen angepasst, die im Zuge der 2012 abgeschlossenen Sanierung und Neueröffnung des Gesellschaftshauses nötig waren, so die Verlegung des Eingangs Palmengartenstraße. Die komplett überarbeitete und mit einem neuen
Cover versehene Neuauflage umfasst auch viele neue und zusätzliche Fotos. Das Buch ist ab sofort an den Gartenkassen, in der Boutique im Eingang Siesmayerstraße sowie im Buchhandel erhältlich.

$\mathrm{Ob}$ jüngste Veränderungen in den einzelnen Schauhäusern des Tropicariums wie das neu gestaltete Savannen- und Trockenwälder-Haus oder Neupflanzungen vor dem Subantarktishaus und den Alpinhäusern, ob frisch angelegte Themengärten wie das Asien-Beet nahe dem Kleinen Weiher, der sanierte Rosengarten oder neue Steingarten-Areale - alle Angaben in diesem seinerzeit ersten handlichen Führer seit 1913 wurden auf den jüngsten Stand gebracht. Zusätzliche Kapitel behandeln das bereits von der UNESCO ausgezeichnete Pilotprojekt „Kinder im Garten" ebenso wie die 2010 gegründete „Stiftung Palmengarten und Botanischer Garten“. Folglich finden sich auch Informationen über den benachbarten, 2012 in städtischen Besitz übergegangenen früheren Lehrgarten der JohanN WolfGANG VON GOETHE-Universität. In beiden Anlagen verfügt die Stadt Frankfurt nun mit 18000 Arten weltweit über eine der größten kommunalen Sammlungen heimischer und tropischer Gewächse.

Last but not least: Mit einem flexiblen Umschlag im Smart-Cover-Format des Frankfurter Societäts-Verlags hat der Leser ein ebenso brauchbares wie haptisch und optisch ansprechendes Kompendium zur Hand - bei einer Visite des Gartens ebenso wie zur Vor- oder Nachbereitung eines Besuches zu Hause auf dem Sofa, dem Balkon oder der Gartenbank. 